\title{
A Novel In Vitro Model for Determining the Optimum pH and Dose Volume of New Liquid Alginate for Infant Reflux Suppression
}

\author{
Jeanine Fisher ${ }^{1} \cdot$ Fiona McLaughlin ${ }^{2} \cdot$ Neil Fawkes $^{2} \cdot$ Hannah Tipple $^{2} \cdot$ Cathal Coyle $^{2} \cdot$ Peter W. Dettmar $^{1}$ (I)
}

Accepted: 24 June 2021 / Published online: 20 July 2021

(c) The Author(s) 2021

\begin{abstract}
Background Gastroesophageal reflux frequently occurs in infants from birth to 2 years and is characterised by reflux and regurgitation often occurring during or immediately after feeds. These reflux events can range in both frequency and severity, and as the reflux events increase, they become increasingly distressing for both the infant and the parent. The study aimed to characterise the properties of a new infant liquid alginate product, determining the optimum gastric $\mathrm{pH}$ and dose volume for maximum reflux suppressant activity.

Methods An in vitro infant stomach model was designed and developed that allowed products to be assessed for their reflux suppression activity. The validation of the model was completed by three independent operators comparing a milk control with infant Gaviscon to evaluate the models' robustness, reproducibility, and ease of use. The model was used to establish reflux suppression activity of a new liquid alginate infant formulation in comparison with a milk control. Suppression activity was assessed at varying doses and $\mathrm{pH}$ within a physiological range.

Results The validation study demonstrated no significant difference in refluxate volumes for the milk control within each reflux event when comparing across the three individual operators. Similarly, no statistical differences were seen during the infant Gaviscon experiments, confirming the robustness and reproducibility of the model. Significant reflux suppression was seen across the $\mathrm{pH}$ range (except at $\mathrm{pH}$ 5.75); the $\mathrm{pH}$ most advantageous for reflux suppression was $\mathrm{pH}$ 5.25. The optimum dose volume for consistently suppressing reflux was shown to be $5 \mathrm{ml}$. An infant stomach model was designed for evaluating reflux suppression activity of a formulation of liquid alginate. The optimum gastric $\mathrm{pH}$ and dose volume for demonstrating significant reflux suppression and the thickening of formula milk by the infant liquid alginate formulation were established. Conclusion This study confirms the mode of action of the alginate formula, demonstrating a superior reduction in the retrograde movement of in vitro gastric contents and volume of regurgitation. The study also demonstrates that optimal performance occurs in conditions that are in line physiologically with the target patient. Both actions compliment and support the efficacy of the alginate formulation as a reflux therapy agent.
\end{abstract}

\section{Introduction}

Gastresophageal reflux (GER) is a common presentation in babies and infants and is caused by the involuntary retrograde movement of gastric contents into the esophagus, resulting in reflux and regurgitation, especially during and following feeds $[1,2]$. It is primarily related to the developmental immaturity of the lower esophageal sphincter,

Peter W. Dettmar

peter.dettmar@technostics.com

1 Technostics Limited, Castle Hill Hospital, Daisy Building, Castle Road, Cottingham HU16 5JQ, East Yorkshire, UK

2 Reckitt, Digestive Relief, Dansom Lane, Hull HU8 7DS, UK resulting in episodes of transient lower esophageal sphincter relaxation [3-5]. A second mechanism known to initiate reflux is increased abdominal pressure overcoming the esophageal sphincter pressure, which is low in early birth infants $[1,3,5,6]$. Further infant anatomical characteristics including a short and narrow esophagus, use of high-calorie liquid diet, and a recumbent position increase the occurrence of reflux and regurgitation of feeds [7]. It is important to note that paediatric reflux is distinct from acid reflux disorders in adults, where the acid pocket, rather than a near neutral $\mathrm{pH}$ milk feed, plays a vital role in the initiation of symptoms.

With increased frequency and severity, GER can become pathological and develop into gastroesophageal reflux disease (GERD), especially in cases of prematurity, decreased 


\section{Key Points}

Development and validation of a robust and reproducible infant reflux suppression model.

Demonstrated significant reflux suppression with a newly developed liquid infant product.

Dose volume of liquid alginate infant and optimum $\mathrm{pH}$ for reflux suppression determined.

neural protective reflexes, and pulmonary problems [8]. These patients often present with troublesome symptoms arising from the passage of gastric contents into the esophagus and, with increased severity, can be accompanied by failure to thrive and respiratory problems $[4,8]$.

Considering the same symptoms are exhibited for GER and GERD, those being recurrent reflux, regurgitation, excessive crying, and irritability [9], it is recognised that a continuum exists between physiological GER and GERD [9] and that the conditions should not be viewed as two distinct forms requiring individual treatment approaches, but rather as a disease spectrum, where infants can present with symptoms ranging in severity, which should be treated accordingly.

Regurgitation is a dominant symptom of infant reflux. The average worldwide prevalence is estimated to be $30 \%$, when using Rome III criteria (two or more regurgitation episodes per day for more than 3 weeks) or North American Society for Pediatric Gastroenterology, Hepatology, and Nutrition (NASPGHAN)/European Society for Paediatric Gastroenterology, Hepatology, and Nutrition (ESPGHAN) guidelines [10].

Persistent and frequent regurgitation can be distressing for the baby/infant and highly distressing for the parent/carer [11-13]. Worrisome infant reflux can lead to prolonged sleep deprivation, stress, anxiety, and frustration, all of which can negatively affect the bond between parent and child [14].

Treatment options for infant reflux currently include non-pharmacological interventions (NPIs) such as parental advice (avoid over-feeding), thickened feeds, protein hydrolysate or amino acid-based formula, or elimination of cow's milk in maternal diet if infants are being breastfed. NPIs are typically used as first-line treatment in infants and children who do not have features requiring early referral [15].

Feed thickeners are a common treatment of GER in infants $[16,17]$ and are thought to contribute to the reduction of reflux of gastric content into the esophagus by increasing the density and viscosity of the liquid.

These approaches are usually followed by pharmacological acid suppression with histamine receptor antagonists and/or proton pump inhibitors (PPIs) [8]. Unlike adults, acid is not seen to play a major role in infant reflux, apart from in those with demonstrable esophagitis. Therefore, acid suppression is not considered appropriate for most infants, where the pathophysiology pertains to an immature lower esophageal sphincter. Nonetheless, the prescriptions issued for PPIs for infants suffering from troublesome reflux have increased significantly over recent years [4, 18], and acidsuppressant therapies have become the mainstay of reflux management, despite reports of a lack of efficacy in this age group [19, 20].

In some markets, alginates are also recommended on the patient pathway, as a step up from feed thickeners and before acid suppression medication, a recommendation endorsed by the British National Institute for Health and Care Excellence (NICE) [15]. Alginate preparations have proven efficacy in the treatment of GERD in adults [21] and regurgitation in babies and infants [5, 22-25]. There are, however, marked differences in the mode of action between the adult and the infant alginate products. In the adult product, the alginate reacts with gastric acid to produce alginic acid and forms a floating raft on top of the stomach contents, suppressing reflux into the esophagus, whereas the mode of action of the infant alginate product is by the promotion of cross-linking by calcium ions and milk proteins present in the feed, increasing viscosity, which adds to gelling and thickening of the feed, limiting the retrograde movement from stomach into the oesophagus and beyond. This is especially important post feeding, which is the time when babies and infants present with maximum symptoms.

As with all clinical investigations, but perhaps more so in infants, due to the vulnerability of the population, ethical factors need to be considered. It is, therefore, valuable to conduct initial research in the laboratory setting. A novel in vitro infant stomach model has recently been developed and validated for characterising a new feed-thickening product for suppressing reflux in neonates and infants. This newly developed model contains an artificial stomach, which will stimulate internal reflux and measure the height and amount of reflux travelling up the infant oesophagus.

Using the newly developed model, the aim of the study was to characterise the properties of a new liquid alginate infant product, determining the optimum gastric $\mathrm{pH}$ and dose volume for maximum reflux suppression activity.

\section{Materials and Methods}

\subsection{Materials}

Infant Gaviscon, the new alginate reflux suppressant formulation (the liquid alginate infant formulation), and the milk control (Infant Formula Milk, SMA Pro) used throughout 
the study were provided by Reckitt (Dansom Lane, Hull, East Yorkshire, UK). The analytical grade $1 \mathrm{M}$ hydrochloric acid $(\mathrm{HCl})$ used throughout the study was purchased from Fisher Scientific. The infant stomach model was designed, developed, and validated by Technostics Limited (Castle Hill Hospital, Cottingham, East Yorkshire, UK). The model used a urinary drainage bag purchased from Great Bear Healthcare and was used as an artificial stomach.

\subsection{Method: Validation of the Infant Stomach Model}

The infant stomach model was developed to evaluate and identify new products in the treatment of GER in neonates and infants (Fig. 1). As far as we are aware, this is the first in vitro model developed to screen and evaluate new products in this area. The model was validated by carrying out experiments comparing the refluxate volumes of a milk control and infant Gaviscon. Three operators who were not blinded conducted the experiments to demonstrate the model's robustness, ease of use, and reproducibility.

The infant stomach model includes a piece of tubing 12 $\mathrm{cm}$ in length, to mimic an infant esophagus [26], marked with 1-cm increments to allow for measurements of any reflux activity. The total volume of the artificial stomach was $85 \mathrm{ml}$ (Fig. 2). By applying a measured volume of air and using the force provided by a $0.3 \mathrm{-kg}$ weight, a level of refluxate was achieved for the milk control in comparison to infant Gaviscon. The optimum dose response curves at

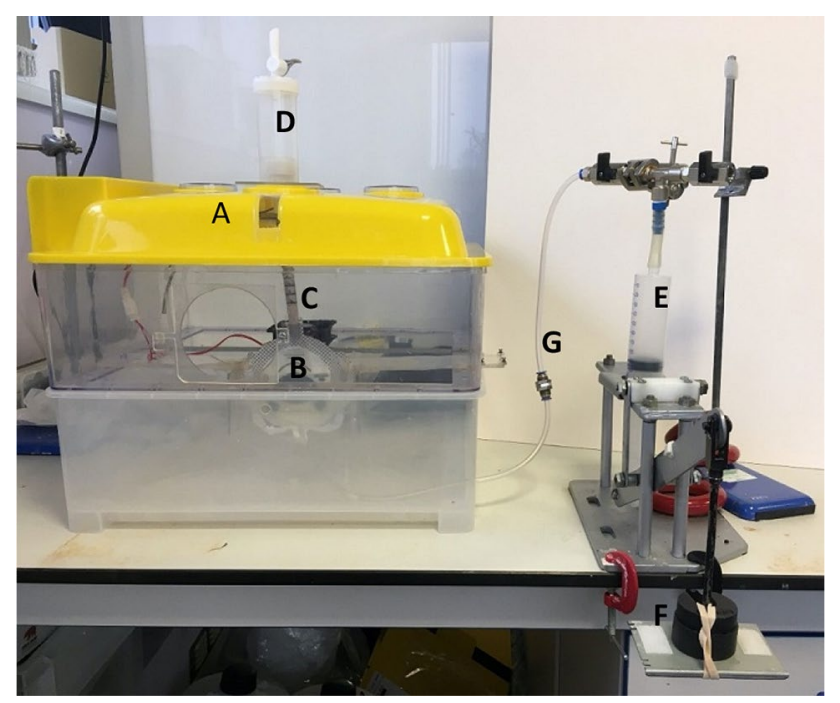

Fig. 1 Infant stomach model capable of simulating internal reflux. A. Heated $\left(37^{\circ} \mathrm{C}\right)$ incubation unit. B. Infant artificial stomach $(85 \mathrm{ml})$. C. Infant esophagus $(12 \mathrm{~cm})$ marked with $1-\mathrm{cm}$ increments. Reflux height recorded. D. Reflux collection vessel. Volume measured. E. Air via $100-\mathrm{ml}$ syringe. F. Force provided by $0.3 \mathrm{~kg}$ weight. G. Creation of reflux event connected to bottom of stomach by one way value

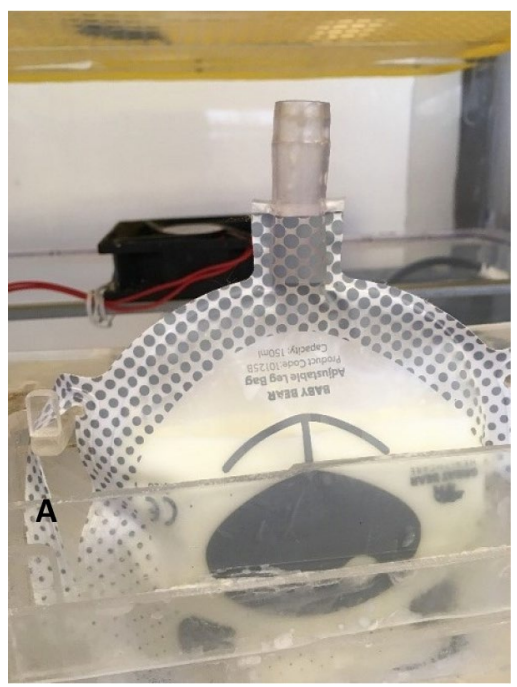

Fig. 2 85-ml stomach volume

a weight of $0.3 \mathrm{~kg}$ and at a range of internal pressures are shown in Fig. 3, and as would be expected, compared to the milk control, the level of refluxate was suppressed to a far greater extent by infant Gaviscon.

Each operator carried out 24 experiments including milk control (Infant Formula Milk, SMA Pro) $\times 12$ and the Infant Formula Milk (milk formulation) with addition of infant Gaviscon $\times 12$ (five reflux events per experiment). Experiments were carried out in a randomised order. The milk control formulation was prepared by adding $12.9 \mathrm{~g}$ (three scoops) of SMA Pro to $90 \mathrm{ml}$ of $\mathrm{H}_{2} 0$ at $37^{\circ} \mathrm{C}$ and shaking well for $1 \mathrm{~min}$. $1 \mathrm{M} \mathrm{HCl}$ was used to adjust the $\mathrm{pH}$ to the optimum $\mathrm{pH}$ for product efficacy, with the temperature maintained at $37^{\circ} \mathrm{C}$. Experiments using the milk control began with adding $35 \mathrm{ml}$ of milk control to the urinary drainage bag used as the infant stomach; next, 15 $\mathrm{ml}$ of $\mathrm{H}_{2} \mathrm{O}$ at $37^{\circ} \mathrm{C}$ was added to the artificial stomach then an additional $35 \mathrm{ml}$ of milk control was added to the artificial stomach, totalling $85 \mathrm{ml}$ (Fig. 2). After $5 \mathrm{~min}$, a reflux event was created by applying $100 \mathrm{ml}$ of air via a syringe and using the force provided by dropping a $0.3-\mathrm{kg}$ weight, which produced a reflux event that was both measurable and collectable $(\mathrm{g})$, and the height the reflux event travelled (mm) within the model was also recorded, as illustrated in Fig. 1. Any refluxed milk control was replenished. The experiment was repeated until five reflux events had been conducted. Reflux events were carried out at 5-min intervals. Experiments using infant Gaviscon began with the addition of $35 \mathrm{ml}$ of milk formulation to the artificial stomach then the addition of a dose of the infant Gaviscon (each sachet $[0.65 \mathrm{~g}]$ was mixed with $5 \mathrm{ml}$ of $\mathrm{H}_{2} 0$ until a paste was formed [approximately $1 \mathrm{~min}$ ], then $10 \mathrm{ml}$ of $\mathrm{H}_{2} \mathrm{O}$ was added and mixed (approximately $30 \mathrm{~s}$ ); the 


\section{$0.3 \mathrm{~kg} / 85 \mathrm{ml}$}

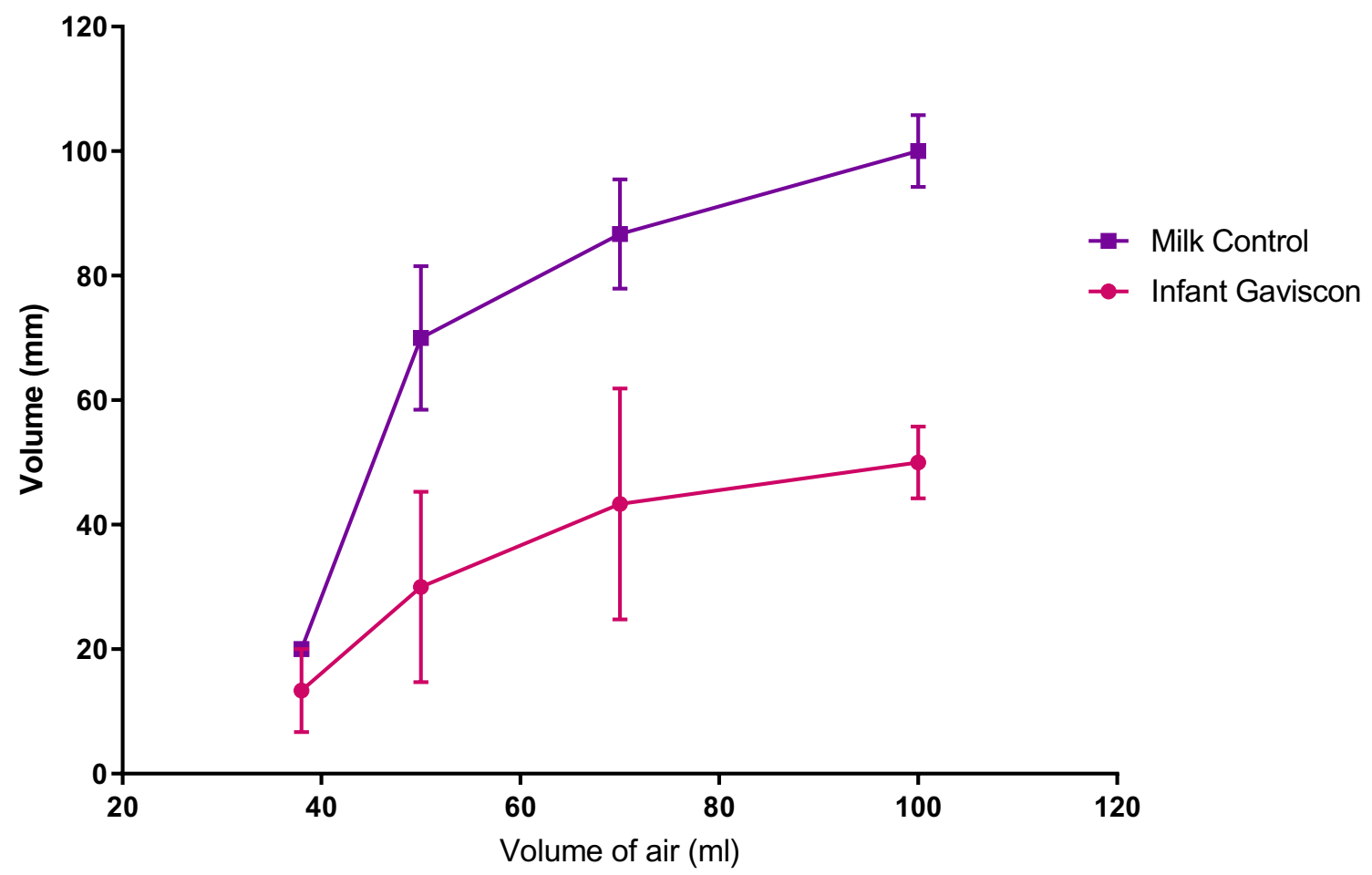

Fig. 3 The level of refluxate using a $0.3-\mathrm{kg}$ weight and at varying pressures (volume of air) with a stomach volume of $85 \mathrm{ml}(n=3 \pm \mathrm{SEM})$

15-ml mixture was then added to the artificial stomach via a syringe). The additional $35 \mathrm{ml}$ of milk formulation was added to the artificial stomach. After $5 \mathrm{~min}$, a reflux event was created as previously described. The experiment was repeated until five reflux events had been conducted. Reflux events were carried out at 5-min intervals. The artificial stomach and its contents were housed in a heated incubation unit to maintain a temperature of $37 \pm 0.5^{\circ} \mathrm{C}$ for the duration of the experiments.

\subsection{Method: Infant Stomach Model}

The infant stomach model was utilised to establish any reflux suppression properties of the liquid alginate infant formulation in contrast to milk control. Varying dose volumes of the liquid alginate infant formulation were investigated at a range of $\mathrm{pH}$ levels $(2.5 \mathrm{ml}$ at $\mathrm{pH} 5.25$, $5 \mathrm{ml}$ at $\mathrm{pH} 4.5,5.0,5.25,5.50$, and 5.75 , and $10 \mathrm{ml}$ at $\mathrm{pH}$ 5.25). Experiments for each dose volume were performed, including the milk control $\times$ six (five reflux events per experiment). Experiments were carried out in a randomised order. The milk control formulation was prepared by adding $12.9 \mathrm{~g}$ (three scoops) of SMA Pro to $90 \mathrm{ml}$ of $\mathrm{H}_{2} \mathrm{O}$ at $37^{\circ} \mathrm{C}$ and shaking well for $1 \mathrm{~min}$. $1 \mathrm{M} \mathrm{HCl}$ was used to adjust to the required $\mathrm{pH}$. Temperature was maintained at $37{ }^{\circ} \mathrm{C}$. Experiments using milk control began with adding $40 \mathrm{ml}$ of milk control to the urinary drainage bag used as the infant stomach; next, $5 \mathrm{ml}$ of $\mathrm{H}_{2} \mathrm{O}$ at $37^{\circ} \mathrm{C}$ was added to the artificial stomach, then a further $40 \mathrm{ml}$ of milk control was added to the artificial stomach, totalling $85 \mathrm{ml}$ (Fig. 2). After $5 \mathrm{~min}$, a reflux event was created as previously described. The experiment was repeated until five reflux events had been conducted. Reflux events were carried out at 5-min intervals. Experiments using the liquid alginate infant formulation began with addition of half of the milk formulation volume (at the specified $\mathrm{pH}$ range), followed by addition of the required dose of the liquid alginate infant formulation and then the remaining milk formulation, to reach a total volume of $85 \mathrm{ml}$ within the artificial stomach. After $5 \mathrm{~min}$, a reflux event was created as previously described. The experiment was repeated until five reflux events had been conducted. Reflux events were carried out at 5-min intervals. The artificial stomach and its contents were housed in a heated incubation unit to maintain a temperature of $37 \pm 0.5^{\circ} \mathrm{C}$ for the duration of the experiments.

\subsection{Statistical Analysis}

All analysis was performed using analysis of variance (ANOVA), and $t$ test analysis was conducted using GraphPad Prism 8.3.0. 


\section{Results}

\subsection{Validation Study}

The validation study used three trained operators to investigate the difference in response between milk control and infant Gaviscon using the infant stomach model. The study demonstrated no significant difference in refluxate volumes for the milk control within each reflux event and when comparing the three individual operators, a total of 72 experiments. This demonstrated the model's robustness and reproducibility. The validation and reproducibility of the model was first described by Fisher et al. [27]. No statistical differences were seen between operators within each reflux event during the infant Gaviscon experiments, which again highlighted the model's reproducibility. Figure 4 illustrates the reflux suppression properties of infant Gaviscon, with all three operators reporting a significant difference in reflux measured when compared to the milk control. The infant stomach model offered a reliable in vitro method to differentiate between milk control and various products that could be used to treat infant reflux.

\subsection{Characterisation of New Liquid Alginate Infant Formulation}

Figure 5 illustrates the total reflux collected (weight, g) for the milk control at each of the five $\mathrm{pH}$ levels evaluated $\mathrm{pH}$ $4.5,5.0,5.25,5.5$, and 5.75). Based on the mean +1 SD

\section{Total reflux collected after 5 reflux events}

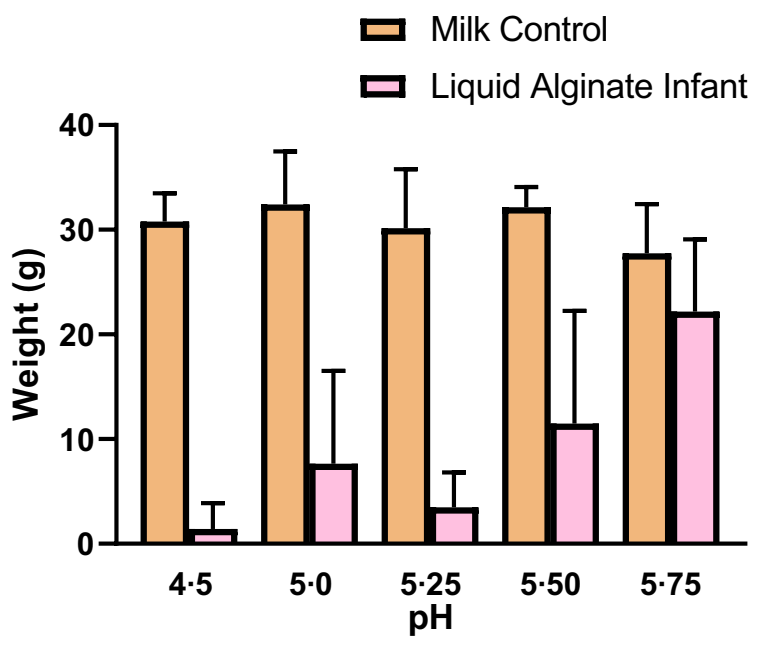

Fig. 5 The total mean amount of refluxate collected with a 5-ml dose of the liquid alginate infant formulation $(n=6,+1$ SD)

of six reflux events, there was no significant difference in the milk control refluxate amount at the varying $\mathrm{pH}$ levels evaluated. When the milk control refluxate levels were compared with the refluxate levels post liquid alginate infant formulation, a significant difference $(p \leq 0.05)$ in the amount of refluxate collected was observed. This was significant at each $\mathrm{pH}$, with the exception of $\mathrm{pH} 5.75$. Following the use of the liquid alginate infant formulation, there was an increase
Fig. 4 The mean amount of refluxate collected $(n=12,+$ $1 \mathrm{SEM}$ ) comparing milk control to infant Gaviscon

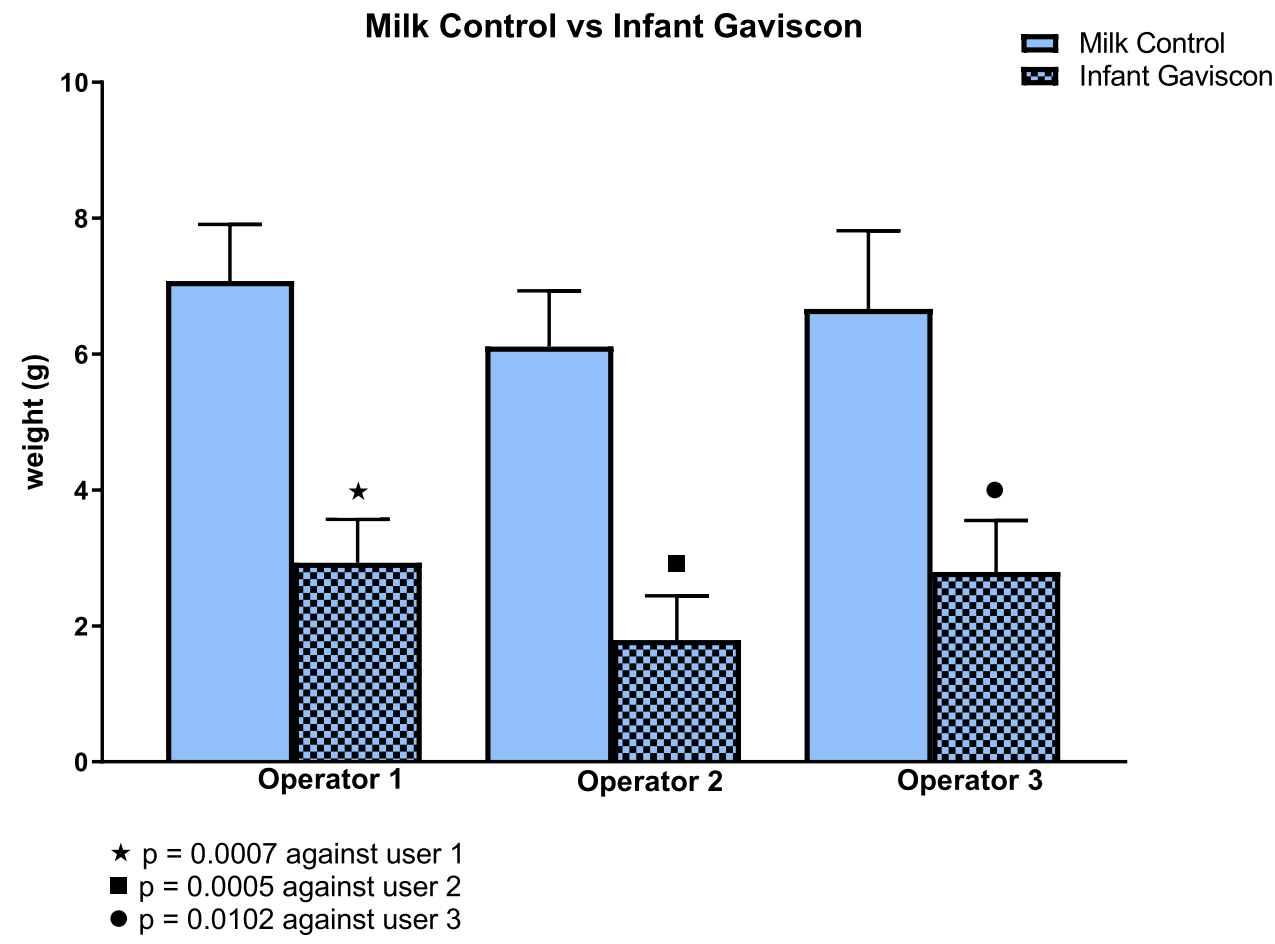


Total reflux collected at $\mathrm{pH} 5 \cdot 25$ at varying doses of Liquid Alginate Infant and Milk Control

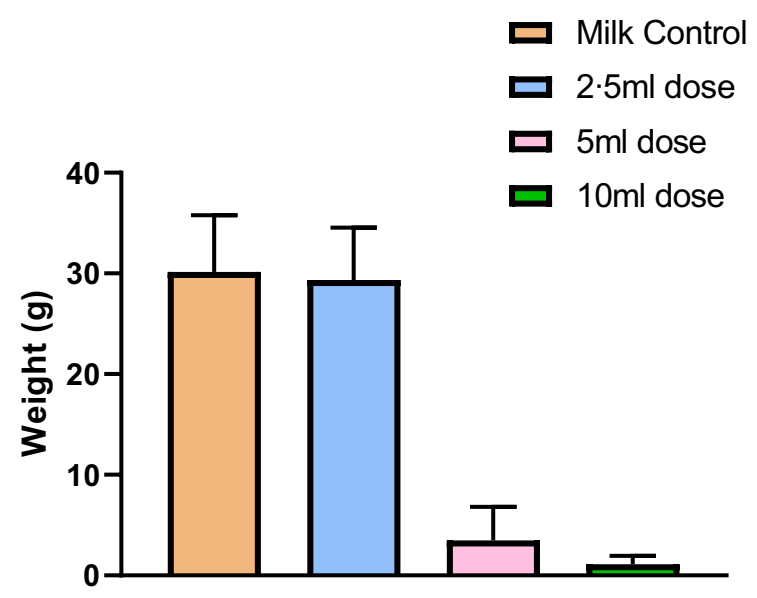

Fig. 6 The total mean amount of refluxate collected $(n=6,+1$ SD)

in the amount of refluxate collected as the $\mathrm{pH}$ increased, which was significantly $(p \leq 0.05)$ different between $\mathrm{pH}$ 4.5 (1.42 g of refluxate collected) and pH 5.75 (22.20 g of refluxate collected).

The $\mathrm{pH}$ selected for further studies evaluating dose volumes of the liquid alginate infant formulation was $\mathrm{pH} 5.25$. Figure 6 illustrates the total mean $+1 \mathrm{SD}(n=6)$ volume of refluxate collected at a range of dose volumes for the liquid alginate infant formulation at $\mathrm{pH} 5.25$. There was no significant difference between the milk control and the liquid alginate infant formulation at a dose volume of $2.5 \mathrm{ml}$ (29.36 g of refluxate collected). However, there was a significant difference $(p \leq 0.0001)$ between the milk control when compared to the liquid alginate infant formulation with a $5-\mathrm{ml}$ and $10-\mathrm{ml}$ dose. The $5-\mathrm{ml}$ dose (3.37 $\mathrm{g}$ of refluxate collected) and the $10-\mathrm{ml}$ dose (1.12 $\mathrm{g}$ of refluxate collected) significantly ( $p \leq$ 0.0001 ) suppressed refluxate compared to the $2.5-\mathrm{ml}$ dose.

Accounting for all the dose volumes $(2.5 \mathrm{ml}, 5 \mathrm{ml}$, and $10 \mathrm{ml}$ ) of the liquid alginate infant formulation evaluated, the 5-ml dose was the optimum dose volume for consistently demonstrating significant reflux suppression properties.

\section{Discussion}

The management of infant reflux has persistently presented challenges, likely due to the difficulty of diagnosing GER and GERD, a lack of effective medications, and the ethical considerations about performing clinical studies in babies and infants.

It may be that considering GER and GERD as two separate conditions has hindered effective treatment. May well lead to over medication with acid suppression in some infants even when acid is not a contributing factor or can lead to a failure to step up from NPIs, resulting in severe distress and impaired quality of life for infants and parents or carers. When considering infant reflux as a disease spectrum, it seems logical to focus on and treat the individual presenting symptoms. For example, management of regurgitation, a primary symptom on the GER/GERD disease spectrum, should include effective parental reassurance supplemented with symptom relief methods like thickeners [28].

Alginates are high-potency, low-volume thickening agents, intended to thicken the contents within the stomach during feeding by increasing viscosity, ultimately increasing the density and weight of the liquid, helping to retain the contents in the stomach and, thus, reduces the likelihood of regurgitation.

This has been demonstrated clinically [22, 23], where a significant reduction in the number and severity of reflux episodes was observed. As mentioned previously, clinical evidence has led NICE to issue guidelines supporting the use of alginate as an appropriate treatment option in infants with frequent regurgitation and signs of distress or irritability not improving with dietary management [29].

Consistent with the NICE guidelines, the Cochrane review of 2014 supported alginate formulations, namely Gaviscon Infant, stating that it improved symptoms in infants, including those with regurgitation and functional reflux [30].

There is the possibility that because alginate-based treatments for babies and infants are not available in Northern America and in many European countries, NASPGHAN and ESPGHAN considered the evidence regarding efficacy to be insufficient to recommend alginates in the guidelines published in 2018 [8]. The NASPGHAN/ESPGHAN guidelines report the data on alginates to be insufficient and inconclusive. This could be attributed to the lack of distinction between antacids and alginates by the reviewers and/or the issue that regurgitation is largely not an acid-related condition. It follows from this that antacids would have little efficacy and alginates, by acting as feed-thickening agents, would.

The current Gaviscon Infant formulation is a powder and contains two alginates, sodium alginate and magnesium alginate $(225 \mathrm{mg}$ and $87.5 \mathrm{mg}$ per $10 \mathrm{ml}$, respectively), and when the formulation is taken in conjunction with milk feeds, it thickens the contents of the infant's stomach. The aim of the current study was to characterise the properties of a new liquid alginate infant product formulated as a suspension with an equivalent alginate concentration and to determine the optimum gastric $\mathrm{pH}$ and dose volume for maximum reflux suppression activity. To do this, validation of the infant stomach model was required to ensure it effectively measured regurgitation episodes. The model was designed to 
simulate internal reflux and allowed for the measurement of the height and the amount of reflux travelling up the artificial esophagus. The model was housed in a $37{ }^{\circ} \mathrm{C}$ temperaturecontrolled environment. Having a working model enabled the primary aim of this study to be met, the endpoint being to fully characterise a newly developed liquid alginate infant suspension formulation prior to clinical evaluation.

Looking in more detail at the experimental data, the results clearly show that both infant Gaviscon (powder) in the validation study and the liquid alginate infant formulation (suspension) in the main infant stomach model evaluation study suppressed reflux. The water content of both formulation types was similar, with $85 \mathrm{ml}$ of each added to the artificial stomach model. In all experiments, the liquid alginate infant formulation was compared directly with a milk control. All experiments were repeated until five reflux events had been conducted at 5-min intervals and each experiment repeated six times.

The first step to characterising the properties of the liquid alginate product was assessment of performance across a range of $\mathrm{pHs}$. This $\mathrm{pH}$ range tested was that shown to be the intragastric $\mathrm{pH}$ of healthy infants [31]. Significant differences were seen between the milk control and the liquid alginate infant formulation at each $\mathrm{pH}$ point tested except for $\mathrm{pH}$ 5.75, providing evidence for the suppression of reflux and the thickening activity of the new formulation within applicable physiological conditions.

The strength of the new infant stomach model was that it could differentiate between $\mathrm{pH}$ levels and the lowest reflux amounts, and the greatest reflux suppression was observed at $\mathrm{pH} 4.5,5.0$, and 5.25. The $\mathrm{pH}$ selected for testing the optimum dose volume was $\mathrm{pH}$ 5.25; not only was this $\mathrm{pH}$ most advantageous for reflux suppression, it was a representation of typical physiological conditions [32].

There was no difference between the milk control and low dose volumes of the liquid alginate infant formulation, indicating that this concentration of alginate did not exert a significant thickening action. It was the high dose volumes $(5 \mathrm{ml}$ and $10 \mathrm{ml}$ ) that demonstrated thickening activity and greater viscosity as well as a reduction in the volume of refluxate collected, significantly suppressing reflux ( $p \leq$ 0.0001 ). Given there was little difference seen between the suppressive action of these higher dose volumes, the 5-ml dose can be considered the minimally effective dose and as such was the optimum dose volume of the liquid alginate infant formulation selected for reflux suppression and the thickening of formula milk for the stomach volume tested.

The model used an 85-ml stomach volume and is, therefore, in line with the recommended volume of milk given to small infants (approximately $3-4 \mathrm{~kg}$ ) [33, 34], and it is also in line with the current Gaviscon Infant dosage recommendations for an infant of this weight [35]. As infants mature and develop, the stomach and feed volume increase; therefore, it is expected that a larger dose of liquid alginate will be required to achieve a reduction in reflux. At present, the in vitro model is not equipped to assess this hypothesis; however, it is a natural next step in this area of research.

Every study has limitations, and in the present study, evaluating different concentrations of alginate could be considered. The $\mathrm{pH}$ levels were well controlled and reported on throughout the study, with five $\mathrm{pH}$ levels evaluated from $\mathrm{pH}$ 4.5 to $\mathrm{pH}$ 5.75. However, future studies should account for the formulation viscosity at the various $\mathrm{pH}$ points and dose volumes evaluated. All formulations contained alginate, and future studies will report on osmolarity between formulations. This is a new developmental model, and the observations and experimental findings need to be evaluated with respect to clinical treatment in neonates and infants.

A further but non-significant observation made was that the refluxate collected decreased as the reflux events increased. This suggests that the reflux suppression properties of the liquid alginate infant formulation improved overtime; this could be attributed to the alginate product mixing with the stomach contents.

\section{Conclusion}

A new infant stomach model was validated to simulate internal reflux and measure the height and the amount of gastric refluxate travelling up an artificial esophagus. The model enabled the primary aim of the study to be investigated and determined. A new liquid alginate infant product was successfully evaluated, demonstrating a significant thickening action across a range of physiological pHs and confirming the optimum dose volume to significantly suppress reflux and to thicken formula milk.

\section{Declarations}

Funding The role of the study sponsor was to provide the experimental formulation of the infant liquid alginate product, review the data interpretation, and support the decision to submit the paper.

Conflict of interest FM, NF, HT, and CC are all employees of the study sponsor, Reckitt, who provided the new formulation of the infant liquid alginate product. PWD and JF received payment for writing and preparing the manuscript for publication.

Ethics approval This is an in vitro study using an in vitro model. There were no patients or human tissue involved in this study and thus the requirement for ethical approval and informed consent were not applicable.

Consent to participate Not applicable as an in vitro model was used and no human tissue or patients were involved. 
Availability of data and material The following additional data will be made available on publication: the experimental data at each $\mathrm{pH}$ and the dose volume evaluated in the infant stomach model.

\section{Code availability Not applicable.}

Author contributions All authors contributed to the study's conception and design. Material preparation and data collection and analysis were performed by JF and PWD. The first draft of the manuscript was written by PWD, JF, and FM, and all authors commented on previous versions of the manuscript. All authors read and approved the final manuscript.

Open Access This article is licensed under a Creative Commons Attribution-NonCommercial 4.0 International License, which permits any non-commercial use, sharing, adaptation, distribution and reproduction in any medium or format, as long as you give appropriate credit to the original author(s) and the source, provide a link to the Creative Commons licence, and indicate if changes were made. The images or other third party material in this article are included in the article's Creative Commons licence, unless indicated otherwise in a credit line to the material. If material is not included in the article's Creative Commons licence and your intended use is not permitted by statutory regulation or exceeds the permitted use, you will need to obtain permission directly from the copyright holder. To view a copy of this licence, visit http://creativecommons.org/licenses/by-nc/4.0/.

\section{References}

1. Czinn SJ, Blanchard S. Gastroesophageal reflux disease in neonates and infants: when and how to treat. Paediatr Drugs. 2013;15(1):19-27. https://doi.org/10.1007/s40272-012-0004-2.

2. Ferguson TD. Gastroesophageal reflux: regurgitation in the infant population. Crit Care Nurs Clin N Am. 2018;30(1):167-77. https://doi.org/10.1016/j.cnc.2017.10.015

3. Huang RC, Forbes D, Davis MW. Feed thickener for newborn infants with gastro-oesophageal reflux. Cochrane Database Syst Rev. 2009. https://doi.org/10.1002/14651858.CD003211.

4. Vandenplas Y, Rudolph CD, Di Lorenzo C, Hassall E, Liptak G, Mazur L, et al. Pediatric gastroesophageal reflux clinical practice guidelines: joint recommendations of the North American Society for Pediatric Gastroenterology, Hepatology, and Nutrition (NASPGHAN) and the European Society for Pediatric Gastroenterology, Hepatology, and Nutrition (ESPGHAN). J Pediatr Gastroenterol Nutr. 2009;49(4):498-547. https://doi.org/10.1097/ MPG.0b013e3181b7f563.

5. Kwok TC, Ojha S, Dorling J. Feed thickener for infants up to six months of age with gastro-oesophageal reflux. Cochrane Database Syst Rev. 2017. https://doi.org/10.1002/14651858.CD003 211.pub2.

6. Taminiau JA. Gastro-oesophageal reflux in children. Scand J Gastroenterol. 1997;223:18-20.

7. NICE C. GORD in children. 2020. https://cks.nice.org.uk/topics/ gord-in-children/background-information/causes/ Accessed 26 Oct 2020

8. Rosen R, Vandenplas Y, Singendonk M, Cabana M, DiLorenzo C, Gottrand F, et al. Pediatric Gastroesophageal Reflux Clinical Practice Guidelines: Joint Recommendations of the North American Society for Pediatric Gastroenterology, Hepatology, and Nutrition and the European Society for Pediatric Gastroenterology, Hepatology, and Nutrition. J Pediatr Gastroenterol Nutr. 2018;66(3):516 54. https://doi.org/10.1097/MPG.0000000000001889.
9. Quitadamo P, Staiano A. Clinical picture of gastroesophageal reflux disease in children. In: Gastroesophageal reflux diseasetheory and research. London: IntechOpen; 2019.

10. Vandenplas Y. Epidemiology. In: Vandenplas Y, editor. Gastroesophageal reflux in children. New York: Springer International Publishing; 2017. p. 5.

11. Vandenplas Y. Diagnosis of gastroesophageal reflux disease. In: Gastroesophageal reflux in children. New York: Springer; 2017. p. 63-74.

12. European Society for Pediatric Gastroenterology, H. a. N. Gastroenterology. http://www.espghan.org/guidelines/gastroenterology/ Accessed 27 Apr 2020.

13. Jung AD. Gastroesophageal reflux in infants and children. Am Family Physician. 2001;64(11):1853-60.

14. RISA (2017) The reflux roller coaster: dismissal, delay and the cost to families and the health system

15. Davies I, Burman-Roy S, Murphy MS. Gastro-oesophageal reflux disease in children: NICE guidance. BMJ. 2015. https://doi.org/ 10.1136/bmj.g7703.

16. Madhoun LL, Siler-Wurst KK, Sitaram S, Jadcherla SR. Feedthickening practices in NICUs in the current era: variability in prescription and implementation patterns. J Neonatal Nurs. 2015;21(6):255-62. https://doi.org/10.1016/j.jnn.2015.07.004.

17. Dhillon AS, Ewer AK. Diagnosis and management of gastrooesophageal reflux in preterm infants in neonatal intensive care units. Acta Paediatr. 2004;93(1):88-93.

18. Barron JJ, Tan H, Spalding J, Bakst AW, Singer J. Proton pump inhibitor utilization patterns in infants. J Pediatr Gastroenterol Nutr. 2007;45(4):421-7. https://doi.org/10.1097/MPG.0b013 e31812e0149.

19. Pasman EA, Ong B, Witmer CP, Nylund CM. Proton pump inhibitors in children: the good, the bad, and the ugly. Curr Allergy Asthma Rep. 2020. https://doi.org/10.1007/s11882-020-00926-4.

20. Van der Pol RJ, Smits MJ, Wijk MPV, Omari T, Tabbers MM, Benninga MA. Efficacy of proton-pump inhibitors in children with gastroesophageal reflux disease: a systematic review. Pediatrics. 2011;127(5):925-35.

21. Chevrel B. A comparative crossover study on the treatment of heartburn and epigastric pain: liquid Gaviscon and a magnesium—aluminium antacid gel. J Int Med Res. 1980;8(4):300-2. https://doi.org/10.1177/030006058000800411.

22. Miller S. Comparison of the efficacy and safety of a new aluminium-free paediatric alginate preparation and placebo in infants with recurrent gastro-oesophageal reflux. Curr Med Res Opin. 1999;15(3):160-8. https://doi.org/10.1185/03007999909114087.

23. Del Buono R, Wenzl TG, Ball G, Keady S, Thomson M. Effect of Gaviscon Infant on gastro-oesophageal reflux in infants assessed by combined intraluminal impedance/pH. Arch Dis Childh. 2005;90(5):460-3. https://doi.org/10.1136/adc.2002.024463.

24. Baird DC, Harker DJ, Karmes AS. Diagnosis and treatment of gastroesophageal reflux in infants and children. Am Family Physician. 2015;92(8):705-14.

25. Smith A, Kotze H, Fawkes N, Coyle C. A meta-analysis to evaluate the effect of feed thickeners and alginate-based products in infants with gastro-oesophageal reflux. J Pediatr Gastroenterol Nutr. 2019;68:442. https://doi.org/10.1097/MPG.0000000000 002403.

26. Yang GS, Bishop WP, Smith BJ, Goudy SL, Sato Y, Bauman NM. Radiographic and endoscopic measurements of esophageal length in pediatric patients. Ann Otol Rhinol Laryngol. 2005;114(8):58792. https://doi.org/10.1177/000348940511400802.

27. Fisher J, Boulton KHA, Dettmar PW. Development of an infant stomach model: validation of products targeting reflux in neonates and infants. Ann Esophagus 2021;4. http://dx.doi.org/ 10.21037/ aoe-20-78 
28. Vandenplas Y, Hauser B, Salvatore S. Functional gastrointestinal disorders in infancy: impact on the health of the infant and family. Pediatr Gastroenterol Hepatol Nutr. 2019;22(3):207-16.

29. NICE. Gastro-oesophageal reflux disease in children and young people: diagnosis and management. 2015. https://www.nice.org. uk/guidance/NG1 Accessed 05 May 2020.

30. Tighe M, Afzal NA, Bevan A, Hayen A, Munro A, Beattie RM. Pharmacological treatment of children with gastro-oesophageal reflux. Cochrane Database Syst Rev. 2014;11: CD08550. https:// doi.org/10.1002/14651858.CD008550.pub2.

31. Omari TI, Davidson GP. Multipoint measurement of intragastric $\mathrm{pH}$ in healthy preterm infants. Arch Dis Childh Fetal Neonatal Ed. 2003;88(6):F517-520. https://doi.org/10.1136/fn.88.6.f517.

32. Omari TI, Barnett CP, Benninga MA, Lontis R, Goodchild L, Haslam RR, et al. Mechanisms of gastro-oesophageal reflux in preterm and term infants with reflux disease. Gut. 2002;51(4):475-9. https://doi.org/10.1136/gut.51.4.475.

33. Bergman NJ. Neonatal stomach volume and physiology suggest feeding at 1-h intervals. Acta Paediatr Int J Paediatr. 2013;102(8):773-7. https://doi.org/10.1111/apa.12291.

34. Zangen S, Di Lorenzo C, Zangen T, Mertz H, Schwankovsky L, Hyman PE. Rapid maturation of gastric relaxation in newborn infants. Pediatr Res. 2001;50(5):629-32. https://doi.org/10.1203/ 00006450-200111000-00016.

35. RECKITT BENCKISER HEALTHCARE (UK) LTD SUMMARY OF PRODUCT Characteristics. Gaviscon Infant. 2015. https:// www.medicines.org.uk/emc/medicine/21981/SPC/Gaviscon+ Infant. Accessed 19 Jan 2019. 